\title{
MEKANISME DISSOCIATIVE TRANCE DISORDER PADA MAHASISWA
}

\author{
DISSOCIATIVE TRANCE DISORDER MECHANISM AMONG UNIVERSITY \\ STUDENTS
}

\author{
Oleh : \\ Novita Ayu Nafisa Rachman ${ }^{1}$ \\ Pambudi Rahardjo ${ }^{2}$
}

\begin{abstract}
This research aims to examine the mechanism of dissociative trance disorder among university students in Purwokerto. The research focuses on the mechanism of dissociative trance disorder among university students in Purwokerto. The research method is qualitative with a case study approach. There are 4 participants and 4 secondary informants in this research. Those who have experienced dissociative trance disorder become primary informants while those who have close relationships with the primary informants become secondary informants. The data were analyzed by using an interactive model, involving data collection, data reduction, data display, and drawing a conclusion. The research result revealed that there are 4 informants who go through the mechanism in the process of dissociative trance disorder occurrence. The mechanism includes four stages, namely the physical symptoms stage, the pre-loss of consciousness stage, the loss of consciousness stage, and the conscious stage.
\end{abstract}

Keywords: mechanism, dissociative trance disorder, trans dissociative

\begin{abstract}
ABSTRAK
Penelitian ini bertujuan untuk mengkaji mekanisme dissociative trance disorder pada mahasiswa di Purwokerto. Fokus penelitian pada mekanisme dissociative trance disorder pada mahasiswa di Purwokerto. Metode yang digunakan dalam penelitian ini yaitu metode kualitatif dengan pendekatan studi kasus. Informan dalam penelitian ini terdiri dari 4 partisipan dan 4 informan sekunder yaitu individu yang pernah mengalami dissociative trance disorder sebagai informan primer dan individu yang memiliki hubungan kedekatan dengan informan primer dijadikan informan sekunder. Data dalam penelitian di analisis menggunakan model interaktif meliputi pengumpulan data, reduksi data, peyajian data, dan penarikan kesimpulan. Hasil penelitian menunjukkan dari empat informan melalui mekanisme dalam proses terjadinya Dissociative Trance Disorder. Mekanisme tersebut meliputi empat tahapan yaitu tahap simptom fisik, tahap pra kehilangan kesadaran, tahap kehilangan kesadaran, dan tahap sadar.
\end{abstract}

Kata kunci : Mekanisme, Dissociative Trance Disorder, Trans Disosiatif

\section{PENDAHULUAN}

Manusia yang sehat tidak hanya secara fisik, tetapi juga sehat secara psikis. Bebas dari gangguan adalah indikasi manusia yang bermental sehat. Ada berbagai macam gangguan mental (mental disorder), salah satunya adalah gangguan trans disosiatif (dissociative trance disorder) yang termasuk dalam gangguan jiwa ringan. Penelitian During dkk ada 28 artikel yang melaporkan 402 kasus dissociative trance disorder (DTD) di seluruh dunia dalam kurun tahun 1988 sampai 2010, sebagian besar kasus dissociative trance disorder (DTD) terjadi di negara-negara Asia yanitu ditemukan 19 artikel, dan kasus lain di laporkan dari

\footnotetext{
${ }^{1}$ Novita Ayu Nafisa Rachman, Fakultas Psikologi, novitaanrpsi@ gmail.com

${ }^{2}$ Pambudi Rahardjo, Fakultas Psikologi, pam13sai@gmail.com
} 
Eropa 5 artikel, Amerika 2 artikel, dan Afrika 2 artikel. Di Indonesia sendiri dalam penelitian Hidajat (2008) kasus trans disosiatif semakin tahun semakin meningkat, ada 20 kasus di antara tahun 2005-2006, kemudian ada lebih dari 37 kasus di tahun 2007, dan ada 23 kasus yang dilaporkan hanya pada awal 2008.

Trance adalah suatu perubahan status kesadaran dan menunjukkan penururnan responsivitas terhadap stimulus lingkungan, menurut Kaplan (2010). DSM-IV (American Psychiatric Association, 2013) menunjukkan paradigma dalam psikologi bahwa kepribadian manusia hanya satu, namun bisa terpecah. Dissociative Trance Disorder terjadi karena adanya reaksi kejiwaan yang dinamakan reaksi disosiasi atau reaksi yang mengakibatkan hilangnya kemampuan seseorang untuk menyadari realitas disekitarnya, yang disebabkan oleh berbagai faktor seperti tekanan fisik maupun mental serta labilitas kepribadian (Hawari, 2007).

Kriteria trans disosiatif dalam PPDGJ III tidak jauh berbeda dengan diagnosa DSM IV-TR. Pedoman penggolongan dan diagnosis gangguan jiwa III yang memasukkan gangguan trans dalam kelompok gangguan disosiatif (konversi) dengan pedoman diagnostik sebagai berikut : a. Keadaan trance atau trance kesurupan menyebabkan penderitaan yang bermakna secara klinis atau gangguan dalam fungsi sosial, pekerjaan, atau fungsi penting lain. b. Hanya gangguan trans yang involunter (di luar kemauan individu) dan bukan merupakan aktivitas yang biasa dan bukan merupakan kegiatan keagamaan ataupun budaya yang boleh dimasukkan dalam pengertian ini. c. Tidak ada penyebab organik (misalnya epilepsi lobus temporalis, cedera kepala, intoksikasi zat psikoaktif) dan bukan bagian dari gangguan jiwa tertentu, seperti skizofrenia atau gangguan kepribadian muliple (Maslim, 2014).

Siswanto (2015) mengatakan bahwa penyebab Dissociative Trance Disorder tetaplah karena kepribadian yang termasuk didalamnya keyakinan. Situasi atau penyebab terjadinya trans disosiatif bisa dibedakan menjadi dua, yaitu situasi eksternal dan situasi internal. Situasi eksternal yang terdiri dari lokasi dan sugestif yang berkaitan dengan cerita magis dengan lokasi, situasi stres, dan waktu khusus. Situasi internal terdiri dari tubuh lemah dan melamun atau pikiran kosong.

Trans Disosiatif terbagi menjadi tiga fase, pra kehilangan kesadaran, hilang kesadaran, pasca kehilangan kesadaran (Anna \& Michael, 2014) yaitu, tahap Pra kehilangan kesadaran terdapat simtom fisik, tahap berikutnya adalah saat mengalami trans disosiatif, dan tahap pasca kehilangan kesadaran, lebih mudah rentan atau sensitif terhadap stimulus yang berbau gaib atau mistis.

Dalam Kamus Bahasa Indonesia (KBBI), mahasiswa didefinisikan sebagai orang yang belajar di Perguruan Tinggi. Mahasiswa adalah seseorang yang sedang dalam proses menimba ilmu ataupun belajar dan terdaftar sedang menjalani pendidikan pada salah satu bentuk perguruan tinggi yang terdiri dari akademik, politeknik, sekolah tinggi, institut dan universitas (Hartaji, 2012). Mahasiswa yang mengalami trans disosiatif merupakan mahasiswa yang mengalami kehilangan kesadaran sementara akan kesadaran dan identitas dirinya. Disorder Trance Disosiative (DTD) terjadi karena disebabkan faktor psikologis dan kultural yang menimbulkan munculnya stres dan ketegangan kuat (Kartono, 1981).

Kepribadian yang dapat terjadi ketika mengalami Disorder Trance Disosiative (DTD) menurut Kartono (1981) antara lain sangat egositis, selfish, suggestible, memiliki emosi yang kuat, ada kecenderungan yang sangat kuat sekali untuk melarikan diri dari situasi-situasi yang dianggap sebagai suatu hal yang tidak menyenangkan, dan memiliki simptom fisik yang dibuat-buat. Peneliti 
tertarik dengan tema tersebut karena dalam mekanisme terjadinya trans disosiatif yang cenderung terjadi pada malam hari dengan situasi dan kondisi yang berbeda masih belum terlihat bagaimana mekanisme yang terjadi dengan jelas dan mengapa mahasiswa dapat mengalami Dissociative Trance Dosorder.Berdasarkan permasalahan dan studi pendahuluan yang dilakukan maka penelitian ini bertujuan untuk mendeskripsikan mekanisme trans disosiatif yang terjadi pada mahasiswa.

\section{METODE}

Penelitian ini menggunakan metode penelitian kualiatif. Penelitian kualitatif adalah penelitian yang pada umumnya menjelaskan dan memberi pemahaman dan interpretasi tentang berbagai perilaku dan pengalaman manusia (individu) dalam berbagai bentuk. Pendekatan yang digunakan dalam penelitian ini adalah menggunakan metode studi kasus. Studi kasus ini merupakan studi yang mendalam tentang individu dan berjangka waktu relatif lama, terus menerus serta menggunakan objek tunggal, artinya kasus dialami oleh seseorang. Dalam studi kasus ini peneliti mengumpulkan data mengenai diri subjek dari keadaan masa sebelumnya, masa sekarang dan lingkungan sekitar (Furchan, 2007).

Pengambilan sampel diarahkan dengan penemuan individu- individu yang memiliki pengalaman yang sesuai dengan fenomena yang diteliti. Sampel ini menetapkan terlebih dahulu kriteria-kriteria yang telah ditetapkan sebelumnya. Pada peneltian ini, partisipan adalah mahasiswa di Purwokerto yang pernah mengalami Dissociative Trance Disorder (DTD). Partisipan sekunder adalah keluarga dan kerabat yang memiliki kedekatan dengan Partisipan sekunder.

\section{HASIL}

Mekanisme Dissociative Trance Disorder yang terjadi pada empat informan penelitian dapat dilihat berdasarkan dengan faktor penyebab dan karakteristik psikologis. Seperti yang sudah dijelaskan oleh informan, mekanisme yang dialami pertama kali ketika informan sedang merasakan beban pikiran dan emosi yang mengganggu aktifitas, informan merasakan keluhan fisik. Kemudian informan merasakan keterlibatan emosi semakin dalam yang dimana emosi tersebut merupakan tekanan yang pernah dialami oleh informan pada pengalaman di masa lalu yang hingga saat ini masih dirasakan oleh informan.

Informan akan mengalami kehilangan kesadaran ketika sudah merasakan keterlibat emosi yang dialaminya, pada saat informan sedang tidak berada pada kesadarannya, informan cenderung akan lebih dapat menunjukkan ekspresi akan perasaan yang selama ini dirasakan, sehingga informan cenderung akan lebih bersifat agresif. Kemudian setelah kembali pada dnegan kesadarannya, informan akan kembali mengeluhkan kondisi fisik yang dirasakan.

\section{DISKUSI}

Penelitian ini membahas mekanisme Dissociative Trance Diosrders yang terjadi pada mahasiswa berdasarkan faktor penyebab dan karakteristik psikologis yaitu Kebiasaan hidup, Tekanan mental, Bentuk Perlindungan diri (defence mechanism), Pengaruh tekanan mental terhadap Dissociative Trance Disorder, dan Proses terjadinya Dissociative Trance Disorder. Faktor yang dominan dapat memicu terjadinya Dissociative Trance Disorder adalah faktor psikologis, yang meliputi stres, depresi, dan atau semacamnya. Individu yang sedang mengalami atau berada di bawah tekanan sering kali mudah tersugesti dengan berbagai hal 
dikarenakan seringkali melamun yang dinama menandakan sedang kosongnya pikiran sadar. Jika terjadi kekosongan pada pikiran sadar sudah pasti pikiran bawah sadarlah yang mendominasi (Rahmatika, 2018).

Kebiasaan hidup, pola istirahat, pola makan, hingga pola kegiatan yang baik tidak dilakukan secara benar, sehingga hal tersebut membuat Partisipan belum dapat melakukan kebiasaan hidup dengan kedisiplinan yang baik. Kebiasaan hidup yang kurang baik ini menyebabkan tanggung jawab akademis dan non akademis menjadi terhambat. Partisipan cenderung kesulitan dalam merubah kebiasaan hidup menjadi lebih baik karen merasa sudah nyaman akan hal tersebut. Hasil wawancara dengan Partisipan, ketika Partisipan melakukan kebiasaan hidup yang kurang baik, Partisipan akan mendapatkan tekanan yang dapat memicu Partisipan untuk mengalami Dissociative Trance Disorder.

Tekanan mental yang dialami Partisipan mengganggu pikiran maupun perasaan. Keempat Partisipan mengalami tekanan mental yang dialami sejak beberapa waktu yang lalu dan masih membuat Partisipan merasa tertekan hingga saat ini. Tekanan mental yang dialami keempat Partisipan yaitu, kehilangan, perceraian, dan pertengkaran (fisik). Durand, Barlow dan David (2006) menyatakan, kemungkinan besar disoiasi terjadi setelah kejadian-kejadian yang membuat individu mengalami psikis yang melemah atau tekanan mental. Secara kesuluruhan dari keempat Partisipan tidak melakukan bentuk perlindungan diri yang baik. Keempat Partisipan, dalam menghadapi suatu permasalahan akan melakukan perlindungan diri dengan diam dan menghindar. Sikap tersebut tentu membuat Partisipan tidak melakukan bentuk perlindungan diri yang baik.

Menurut pandangan Freud, disosiasi merupakan salah satu bentuk defense mechanism ego ketika kebutuhan id tidak tersalurkan karena adanya superego dalam hal ini orang yang mengalami stres berat tidak dapat mengatasi stressor yang ada sehingga ego melemah. saat ego ini melemah ia mulai melakukan pertahanan diri dalam bentuk disosiasi, yaitu usaha untuk menghilangkan kesusahan atau kekecewaan dengan jalan melarikan diri dari hal-hal yang tak menyenangkan dengan cara yang tidak masuk akal (Sundari, 2015).

Seperti yang dilakukan oleh keempat Partisipan penelitian, ketika Partisipan mengalami permasalahan dan keadaan yang membuat Partisipan merasa tertekan, Partisipan akan melakukan usaha untuk melarikan diri dari masalah dan keadaan tersebut. Dalam hal ini, menurut Kartono (1981) kepribadian penderita Dissociative Trance Disorder memiliki kecenderungan yang sangat kuat sekali untuk melarikan diri dari situasi-situasi yang dianggap oleh partisipan sebagai suatu hal yang tidak menyenangkan.

Dinyatakan bahwa adanya pengaruh antara tekanan mental terhadap DTD. Keempat Partisipan yang mengalami DTD ketika sedang dalam keadaan tertekan. Mahasiswa yang menginjak usia remaja mengalami masa storm and stress, artinya pada masa ini seseorang sangat rentan terhadap pengaruh dan perkembangan sosial. Tuntutan dari orang tua, pendidik, dan teman mungkin saling bertentangan, sehingga remaja yang memasuki masa peralihan menuju kedewasaan seringkali mengalami problem psikis apabila kurang mendapat dukungan psikologis dari orang terdekat (Seifert \& Hoffnung, 1987).

Partisipan seperti gelisah dan susah mengendalikan emosi ketika sedang banyak masalah yang belum terselesaikan baik tugas ataupun dengan lingkungan sosial menyebabkan terjadinya pengaruh antara tekanan mental dengan Dissosiative Trance Disorder. Tekanan mental yang dialami oleh keempat Partisipan yaitu, Partisipan NA mengalami perselingkuhan pada kedua orang tua 
dan kehilangan, Partisipan CM sempat memiliki pengalaman yang hampir sama perselingkuhan pada orang tua, SM mengalami kehilangan, dan GH memiliki pengalaman kekerasan fisik serta pertengkaran dalam keluarga.

Mekanisme tahapan yang meliputi tahap simptom fisik, tahap pra kehilangan kesadaran, tahap kehilangan kesadaran, dan tahap sadar. Berbeda dengan penelitian sebelumnya yang mengatakan bahwa mekanisme Trans Disosiatif terbagi menjadi tiga fase, pra kehilangan kesadaran, hilang sadar, pasca kehilangan kesadaran (Anna \& Michael, 2014). Mekanisme yang dialami dari keempat Partisipan pada penelitian ini dilaui dengan empat tahapan. Yang berbeda adalah pada tahap kedua atau tahap pra kehilangan kesadaran, partisipan kembali merasakan emosi yang pernah dialami pada masa lalu, sehingga tahap ini memberi kejelasan terhadap penyebab terjadi Dissociative Trance Disorder pada mekanisme yang dialami.

\section{KESIMPULAN}

Kesimpulan dalam penelitian ini mekanisme terjadinya Dissociative Trance Disorder terdapat mekanisme dengan beberapa tahapan yang dilalui, pada penelitian ini diperoleh empat tahapan mekanisme yaitu 1) Tahap Simptom Fisik, 2) Tahap pra kehilangan kesadaran, 3) Tahap kehilangan kesadaran, dan 4) Tahap sadar. Secara umum, Partisipan mengalami Dissociative Trance Disorders dipengaruhi oleh faktor penyebab dan karakteristik diagnostik yaitu kebiasaan hidup, tekanan mental, bentuk perlindungan diri, dan kondisi fisik yang tidak menguntungkan bagi partisipan.

Pada penelitian ini ditemukan bahwa pada tahap pra kehilangan kesadaran dalam mekanisme terjadinya Dissociative Trance Disorder merupakan tahapan yang dilalui berdasarkan dengan pengalaman atau tekanan mental yang pernah dialami oleh Partisipan. Pada tahap pra kehilangan kesadaran ini memberikan hubungan yang jelas antara faktor penyebab terhadap terjadi Dissociative Trance Disorder pada mekanisme yang dialami.

Perasaan dengan emosi yang mengacu pada pengalaman di masa lalu keempat Partisipan yang dirasakan saat tahap pra kehilangan kesadaran yang merupakan tahap ketiga mekanisme Dissociative Trance Disorder mempengaruhi reaksi yang terjadi saat Partisipan pada tahap kehilangan kesadaran. Reaksi tersebut merupakan ekspresi atau ungkapan perasaan yang dirasakan oleh Partisipan.

Saran

Bagi peneliti selanjutnya yang akan meneliti untuk dapat mengkaji lebih dalam ketika ingin meneliti dengan tema yang sama yaitu mekanisme terjadinya Dissociative Trance Disorder.

\section{KEPUSTAKAAN}

Anna, N \& Michael. (2014). Dinamika Kesurupan Patologis : Studi Kasus di Jawa Tengah. Jurnal Experientia. Vol.4 No.1.

American Psychiatric Association. (2000). DSM IV TR: Whasington. DC.

Durand, Barlow \& David. (2006). Psikologi Abnormal. Yogyakarta: Pustaka Pelajar. 
Furchan, A. (2007). Pengantar Penelitian dalam Pendidikan. Yogyakarta: Pustaka Pelajar

Hartaji, Damar A. (2012). Motivasi Berprestasi Pada Mahasiswa yang Berkuliah Dengan Jurusan Pilihan Orangtua. Skripsi Fakultas Psikologi Universitas Gunadarma.

Hawari, D. (2007). Pendekatan Holistic Pada Gangguan Jiwa Skizofrenia. Jarakta: Balai Penerbit FKUI.

Hidajat, L. L. (2008). Understanding the Mass Trance Phenomenon in Indonesia: Between Traditional Beliefs and Community Mental Health. Anima, Indonesian Psychological Journal. 23/4: 333- 337.

Kamus Besar Bahasa Indonesia.

Kaplan, H. I., Sadock, B. J. \& Grebb, J. A. (2010). Sinopsis psikiatri ilmu pengetahuan perilaku jilid dua. Jakarta: Binarupa Aksara.

Kartono, K. (1981). Psikologi Abnormal. Bandung: Offset Alumni.

Maslim, R. (2002). Diagnosis Gangguan Jiwa. PPDGJ-III.

Rahmatika, V. (2018). Faktor Psikologis Terhadap Fenomena Kesurupan Yang Terjadi Pada Remaja. Skripsi. Malang.

Siswanto. (2015). Psikologi Kesehatan Mental : Awas Kesurupan! Yogyakarta: Andi.

Sundari, S. (2015). Kesehatan Mental dalam Kehidupan. Jakarta: Rineka Cipta. 